\title{
Mapping current and future European public water withdrawals and consumption
}

\author{
I. Vandecasteele ${ }^{1,2}$, A. Bianchi ${ }^{1}$, F. Batista e Silva ${ }^{1}$, C. Lavalle ${ }^{1}$, and O. Batelaan ${ }^{2,3}$ \\ ${ }^{1}$ Institute for Environment and Sustainability, Joint Research Center of the European Commission, Via Enrico Fermi 2749, \\ 21027 Ispra (VA), Italy \\ ${ }^{2}$ Department of Hydrology and Hydraulic Engineering, Vrije Universiteit Brussel, Pleinlaan 2, 1050 Brussels, Belgium \\ ${ }^{3}$ School of the Environment, Flinders University, G.P.O. Box 2100, Adelaide, SA 5001, Australia
}

Correspondence to: I. Vandecasteele (ine.vandecasteele @ jrc.ec.europa.eu)

Received: 28 February 2013 - Published in Hydrol. Earth Syst. Sci. Discuss.: 29 July 2013

Revised: 9 December 2013 - Accepted: 23 December 2013 - Published: 3 February 2014

\begin{abstract}
In Europe, public water withdrawals make up on average $30 \%$ and in some cases up to $60 \%$ of total water withdrawals. These withdrawals are becoming increasingly important with growing population density; hence there is a need to understand the spatial and temporal trends involved. Pan-European public/municipal water withdrawals and consumption were mapped for 2006 and forecasted for 2030. Population and tourism density were assumed to be the main driving factors for withdrawals. Country-level statistics on public water withdrawals were disaggregated to a combined population and tourism density map (the "user" density map) computed for 2006. The methodology was validated using actual regional withdrawal statistics from France for 2006. The total absolute error (TAE) calculated was proven to be reduced by taking into account the tourism density in addition to the population density.

In order to forecast the map to 2030 we considered a reference scenario where per capita withdrawals were kept constant in time. Although there are large variations from region to region, this resulted in a European average increase of water withdrawals of $16 \%$. If we extrapolate the average reduction in per capita withdrawals seen between 2000 and 2008, we forecast a reduction in average total water withdrawals of $4 \%$. Considering a scenario where all countries converge to an optimal water use efficiency, we see an average decrease of $28 \%$.
\end{abstract}

\section{Introduction}

With increasing demographic pressure on available physical resources, there is a growing need to evaluate and monitor their usage. Public water withdrawals are those made by the municipal water distribution system, and are used mainly for household purposes, although usually they are also used in the commercial and even industrial sectors. In Europe, they account for, on average, $30 \%$ of total water withdrawals (EUROSTAT, 2013). In northern Europe they can account for up to $60 \%$ of withdrawals. Understanding the spatial and temporal patterns in water withdrawals for public use is therefore an important step towards improving the efficiency of use of water resources and reducing water scarcity.

Globally, domestic demand for water has been extensively studied and there have been numerous attempts to describe and model demand (Arbues et al., 2003; Kostas and Chrysostomos, 2006; Wong et al., 2010; Worthington et al., 2006), although mainly at a local or regional level. At these scales, it is possible to take into account such factors as household income and size. There are also several existing models that describe water withdrawals for the public sector at a larger scale (Shiklomanov, 1997; Van Beek et al., 2009; Hoekstra and Mekonnen, 2011). The Global Water Scarcity Information Service (GLOWASIS, 2013; Wada et al., 2011a, b), and the Water - Global Analysis and Prognosis model (WaterGAP, Alcamo et al., 2003) describe the global monthly water demand for the year 2000 at $0.5^{\circ}$ spatial resolution for the domestic sector. The pan-European atlas of water abstractions, losses and returns (Wriedt et al., 


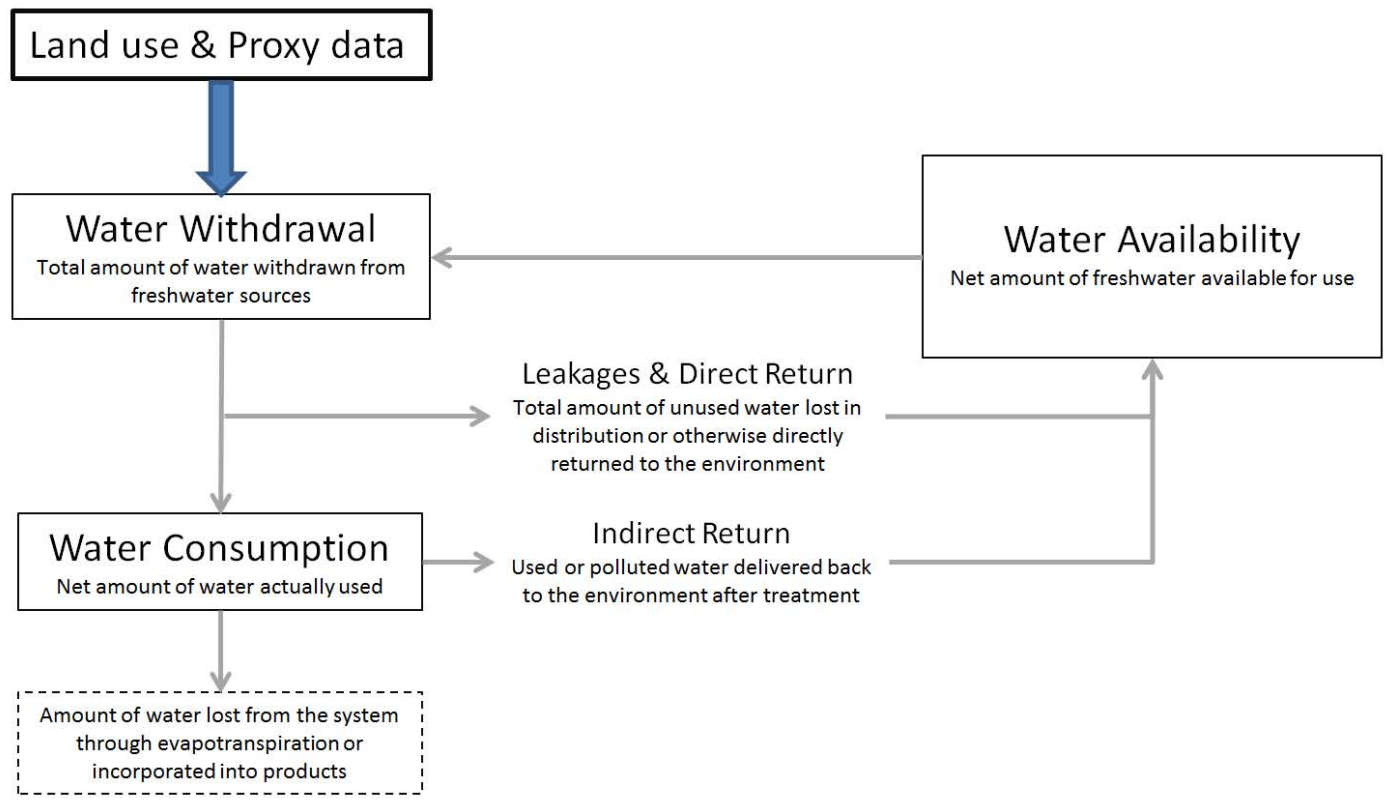

Fig. 1. Conceptual model for the analysis of the water flows. Original definitions are based on UN WWDR (2009).

2008) disaggregated EUROSTAT public water withdrawal statistics to regional level (NUTS3 ${ }^{1}$ ) using the total population. We aim to improve on previous models by providing higher resolution and more up-to-date public withdrawal and consumption maps for Europe. Moreover, the objective is to take into account the impact of additional water withdrawals for the tourism industry, and provide a robust methodology to estimate future public water withdrawals. We propose a methodology based on a strong linkage with land use modeling, which allows us to map future water use trends up to 2030, which is the time horizon up to which the land use model can reliably forecast land use. We use 2006 as the reference year for our mapping and land use model as refined land use maps are available for this year. Additionally, available water withdrawal statistics for 2006 are more complete and consistent than for more recent years.

Figure 1 presents an overview of the terminology and approach used to assess sectorial water flows. Water withdrawal is the gross amount of water extracted from any source in the natural environment for human purposes. Water use is the amount of water that is actually processed in a given sector. Water consumption refers to the part of the processed water that is evaporated, transpired, incorporated into products or crops, consumed by humans or livestock, so heavily polluted that it is no longer suitable for use, or otherwise removed from the immediate water environment. From the total water withdrawal, a part is lost due to leakages during transportation/distribution processes, and thus returned to the natural

\footnotetext{
${ }^{1}$ NUTS (Nomenclature of Territorial Units for Statistics) is the European Union's official regional subdivision of member states, with three hierarchical levels (NUTS1, NUTS2 and NUTS3)
}

environment. In addition, a part of the total used water can potentially be returned to the stock of available water. This share depends on the sector and on the installed capacity to treat water.

In this paper we discuss in detail the methodology used and present the resulting public water withdrawal and consumption maps for 2006 in addition to comparing them to 2030. The methodology is also validated against actual regional statistics and the added value of the inclusion of tourism as a driving factor is also assessed.

\section{Data availability}

The OECD/EUROSTAT Joint Questionnaire on Inland Water provides country-level statistics on annual freshwater abstraction by source and sector and water use by supply category and user (Nagy et al., 2007). The questionnaire covers the EU27 (European Union 27) countries plus Iceland, Norway, Switzerland, Croatia, the Former Yugoslav Republic of Macedonia, Turkey, Bosnia and Herzegovina, and Serbia (although for these countries the data sets are not always complete). For the reference year 2006, we used the average sectorial water withdrawals for the period 2005-2007 from EUROSTAT, which was supplemented by the 2003-2007 average from FAO AQUASTAT (2013) in case data was missing or inconsistent. Where there were still missing values the respective sectorial European average per capita was used. Figure 2 gives an overview of the public water withdrawal for the reference year 2006. The withdrawals have been normalized by the country's total population in order to allow comparison between the countries. 


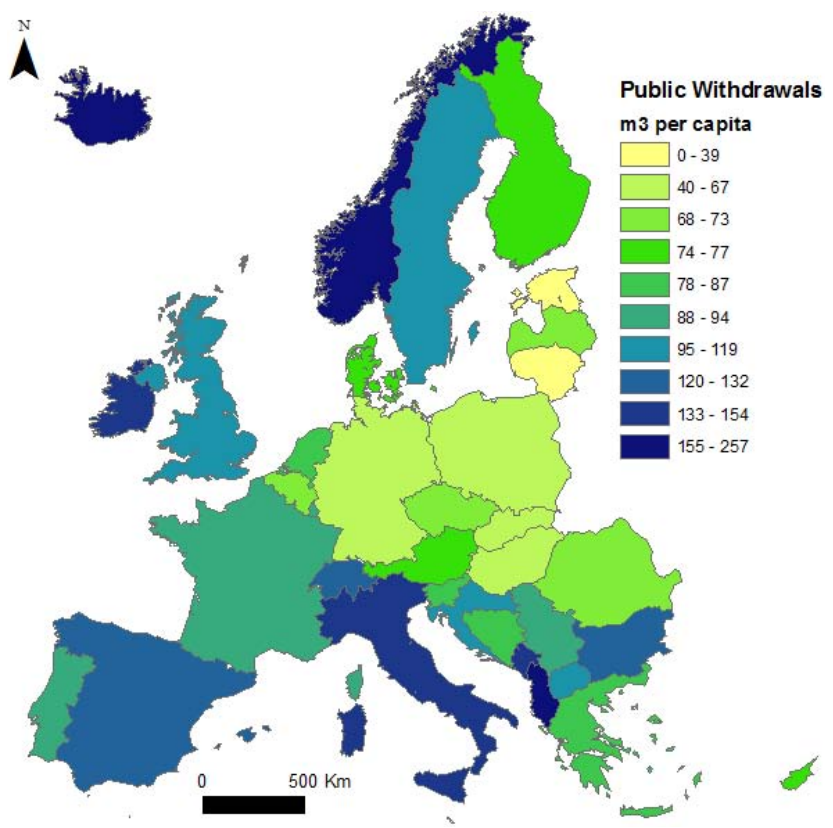

Fig. 2. Map of public water withdrawals per country for the reference year 2006. Values were normalized by the country's total population for comparability and are given in cubic meters per capita.

The data on "public water supply" as provided by the questionnaire is defined as "... (the) water supplied by economic units engaged in collection, purification and distribution of water ... Experience from France: This service includes water for domestic use and water used at offices. It also includes small factories, municipal use ..., and private garden watering" (Nagy et al., 2007). Statistics given on the public supply of water to the different sectors (EUROSTAT, 2013) show that, on average, some $79 \%$ of public water is used for domestic purposes. A further $17 \%$ is used for industrial purposes, and $4 \%$ for agriculture.

Figure 3 shows the relative proportions of public water withdrawals compared to withdrawals for other major waterusing sectors. Interestingly, public water withdrawals make up more than $60 \%$ of the total in northern countries such as the UK, Luxemburg, and Denmark, whilst agricultural withdrawals make up the majority of total withdrawals in the Mediterranean countries of Portugal, Greece, and Spain. Industrial and particularly energy withdrawals (used as cooling water in thermal power plants) are especially important in eastern European countries.

In order to supplement the country-level data provided by EUROSTAT, we collected regional sectorial water withdrawal statistics (at NUTS2, NUTS3 or basin level) from various sources, including each country's national statistical institute and environmental agencies. As the sectorial regional data set for all EU27 countries is incomplete, further analysis has been carried out on the country-level data. Where available, the country-level statistics were verified with the

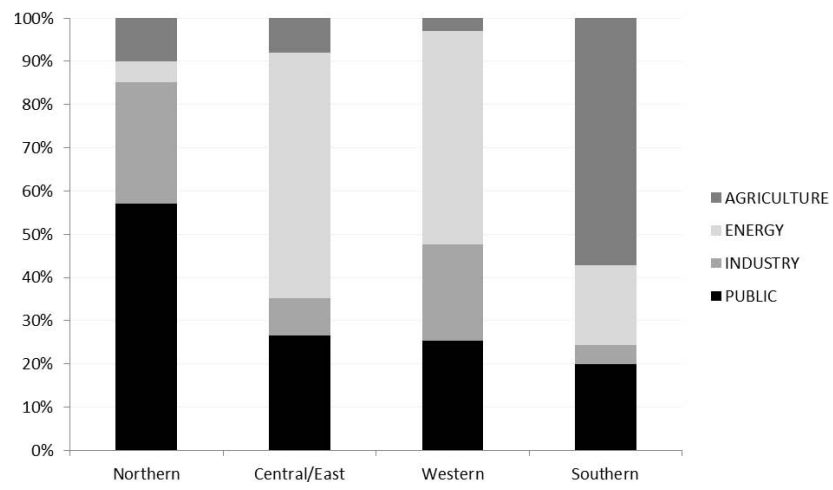

Fig. 3. Sectorial water withdrawals as a percentage of the total withdrawals across European countries for 2006.

regional totals. Since detailed and verified NUTS3 level data was available for France for 2006 (SOeS, 2007), we confirmed our public water withdrawal map for France, produced by disaggregation from the country-level statistics, with actual regional statistics.

\section{Methodology}

We assume the public water withdrawal to be the total water withdrawn in urban areas. Although some commercial/service areas may be included in the land use class, the use is assumed to be mostly domestic, therefore covering the water needs of the resident population within a given area at any time. Since tourism has a large impact in some of the most water scarce areas, we have taken the influence of the additional tourism presence into account.

\subsection{Land use proxy approach}

Our approach links land use data to public water withdrawals. In order to do this for the base year maps we used the 2006 refined version of the CORINE Land Cover (CLC_r, Batista e Silva et al., 2012). The land use needed to map the following years, up to 2030, was modeled using the Land Use Modelling Platform (LUMP). The land use/cover model EUClueScanner, developed at the Joint Research Centre (JRC) Ispra is the core component of this platform, which incorporates several data sources and models (Lavalle et al., 2011). Future land use claims are driven mainly by the CAPRI model (Common Agricultural Policy Regionalized Impact Modelling System), Eurostat data (EUROPOP2008) and CORINE Land Cover trends. As yet, the model is only calibrated for the EU27 member states. The close linkage with the relevant land use classes allows us to both spatially disaggregate the withdrawals at high resolution $(100 \mathrm{~m})$, and to forecast withdrawals based on changing urban land use patterns as simulated by EUClueScanner. As resident and touristic water use was assumed to be present in 
urban areas, both were assigned to the relevant urban land use classes. We additionally assign touristic water use to the land use class "sport and leisure facilities", taking into account extra water used to maintain these infrastructures. Proxy data is used to disaggregate to pixel level and to refine the approach.

An initial analysis of possible proxy data influencing public withdrawals at both country and regional level gives high $R^{2}$ correlations for total population (0.92) and number of nights spent by tourists $(0.82)$. Hence, these variables are selected as being most appropriate to explain public withdrawals at pixel level. Public water withdrawals are therefore assumed to be those made by residents and tourists in urban areas, so that the spatial distribution of the withdrawals is directly related to the combined population and tourist density. Our first step is to compute both the population and tourism densities at the highest resolution possible.

We used a detailed European population density map for 2006 (Batista e Silva et al., 2013), which was produced by disaggregating resident population counts at commune level originating from EUROSTAT to a grid of $100 \mathrm{~m} \times 100 \mathrm{~m}$ cells. The disaggregation approach consisted of redistributing the population totals of each commune among the urban fabric cells as reported in Batista e Silva et al. (2012). In addition, the redistribution was weighted proportionally to the average imperviousness of each urban fabric class, which was used as a proxy for housing density and, therefore, for population density. The source for this data was the European Environment Agency's soil sealing layer $2006^{2}$.

Tourist density maps are created using the number of nights spent by non-residents at NUTS2 level (EUROSTAT, 2013). This data is further disaggregated to NUTS3 level using the number of bed places. The monthly distribution of tourism is calculated using the country-level percentage of nights spent per month. In both cases, national statistics or regional averages are used where data is missing, always taking the closest available year to 2006. The total number of tourists per month (derived from the total number of nights spent) at NUTS3 level for each country is disaggregated to the refined CORINE classes 111 and 112 (urban fabric), and 142 (sport and leisure facilities) to create a map of tourism density at pixel level $(100 \mathrm{~m})$. To correct for outbound tourism, the number of nights spent abroad by residents (EUROSTAT, 2013) per quarter year is also calculated and subtracted from the population density maps. Tourists have a higher water use than residents, which can be explained by the additional water needed to maintain the additional recreational facilities required by tourists, and the higher consumption of water by holiday-makers. The tourist density maps are given a greater weight, by multiplying by a factor of 300/160 (derived from Gössling et al., 2012) when actually assigning the water withdrawals to the users

\footnotetext{
${ }^{2} \mathrm{http} / / / \mathrm{www}$.eea.europa.eu/data-and-maps/data/eea-fast-trackservice-precursor-on-land-monitoring-degree-of-soil-sealing$100 \mathrm{~m}-1$
}

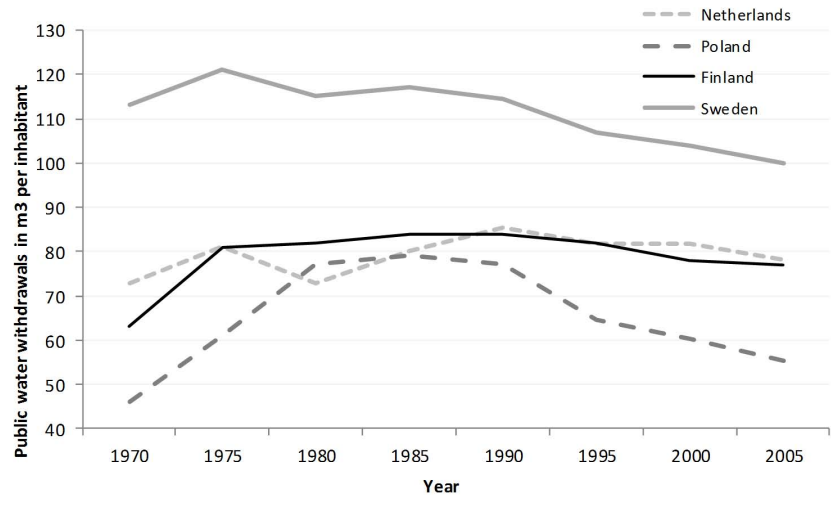

Fig. 4. Trends in public water withdrawals per capita from 1970 to 2005 (EUROSTAT, 2013).

(residents and tourists), thereby assuming that tourists use almost twice the amount of water as residents do.

The monthly maps of weighted number of users of public water per pixel, or "user density", are calculated as

$U=\left(P-T_{0}\right)+300 / 160 \cdot\left(T_{i}\right)$,

where $U$ is the user density; $P$ is the population density (annual map); $T_{0}$ is the number of nights spent abroad by residents (quarterly maps); and $T_{i}$ is the number of nights spent by tourists (monthly maps). Finally, the country-level total public water use is disaggregated according to the user density maps:

$W_{i}=W_{\mathrm{c}} \cdot\left(U_{i} / U_{\mathrm{c}}\right)$,

where $W$ is public water withdrawal; $U$ is the user density; subscript $i$ is the pixel value, and subscript c is the country total value.

For the public sector, consumption is estimated at between 10 and $20 \%$ of withdrawals (UN WWDR, 2009). We assumed the average European public water consumption to be $15 \%$ of the water withdrawal, and computed the consumption maps directly as a fraction of 0.15 of the water withdrawals per pixel.

\subsection{Forecasting to 2030}

The public water withdrawals are forecasted up to 2030 . We combine the land use map, modeled up to 2030 , with projected population statistics, and take country-specific tourism growth rates into account. Figure 4 shows the trends in public water withdrawals for the period from 1970 to 2005 for several countries where consistent data sets were available for all years (EUROSTAT, 2013). The evolution of public water withdrawals per capita differs greatly depending on the country, but we can identify, on average, a decreasing trend in per capita withdrawals over the last $15 \mathrm{yr}$. It can be assumed that water withdrawals per capita should further decrease in time 


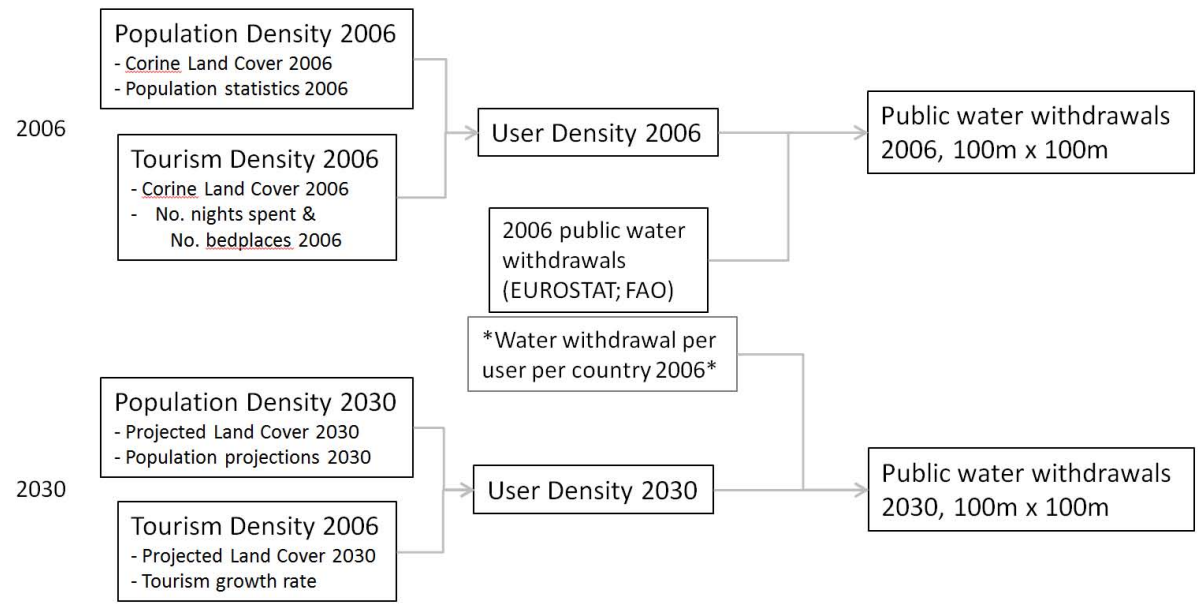

Fig. 5. An overview of the methodology used to map the 2006 and 2030 reference scenario water withdrawals.

with improving efficiency of water use linked to a combination of increasing information dissemination, water pricing, and technological improvements (Flörke and Alcamo, 2004; Gleick, 2003).

Our reference water withdrawal map was computed assuming the water withdrawals per capita are to remain constant in time. In order to also quantify in some way the possible effect that this improving water use efficiency may have on the total water withdrawals over time, we considered two additional scenarios. One corrects the total withdrawals per country in 2030 with a European average efficiency factor, based on the average reduction in per capita withdrawals between 2000 and 2008. The other assumes that by 2030 all countries will converge to have per capita water withdrawals equivalent to those of the most water efficient countries.

Figure 5 summarizes the methodology applied to map the withdrawals for both 2006 and 2030. The projected land use for 2030 is modeled using EUClueScanner. Forecasted population density maps are created using population projections from EUROSTAT, and the tourism density maps are recalculated according to the tourism growth forecasts (at country level) from the Europe vision 2020 report (WTO, 2000). We assume the tourism growth rate for the period 2006-2030 to be equivalent to that predicted for 2010-2020 in the report. Since insufficient data is available on both the regional and monthly distribution of tourism, the 2006 patterns are used. The public water withdrawal per capita is kept constant for the reference scenario, using the 2006 statistics. For the alternative 2030 scenarios, a correction factor to account for improving water use efficiency is applied to the withdrawals forecasted using the reference scenario methodology.

\section{Results}

\subsection{Confirmation of methodology}

In order to confirm our methodology we use detailed and verified NUTS3 level data for France, which is available from the Service de l'Observation et des Statistiques (SOeS, 2007). We compared the actual 2006 total public water withdrawals to those given by summing the estimated withdrawals per NUTS3 region. In order to assess the influence of taking tourism into account in our model, we recalculated the public water withdrawal map based on a disaggregation of the country total water withdrawals directly to the population density, and also compare the NUTS3 totals derived from this map to the actual statistics. Figure 6 compares the regional estimates derived by these two methodologies to the actual statistics.

The Total Absolute Error (TAE) is calculated for both cases as:

$\mathrm{TAE}=\sum_{i}\left|V_{i} Y_{i}\right|$

where $V_{i}$ is the measured value and $Y_{i}$ is the modeled value. The resulting error is 26.56 , or $13.3 \%$ including the tourism density, and a TAE of 27.42 , or $13.7 \%$ using only the population density maps. This shows that, although population density is the main factor contributing to the spatial disaggregation of the statistics, taking the tourism density into account does, in fact, improve the end result.

\subsection{Public water withdrawals in 2006}

Public water withdrawals are mapped at $100 \mathrm{~m}$ resolution at a pan-European scale for the period from 2006 to 2030. Figure 7 shows the withdrawal map for 2006, which has been aggregated to $5 \mathrm{~km}$ resolution for improved visualization. Within each country, the most densely populated areas have 

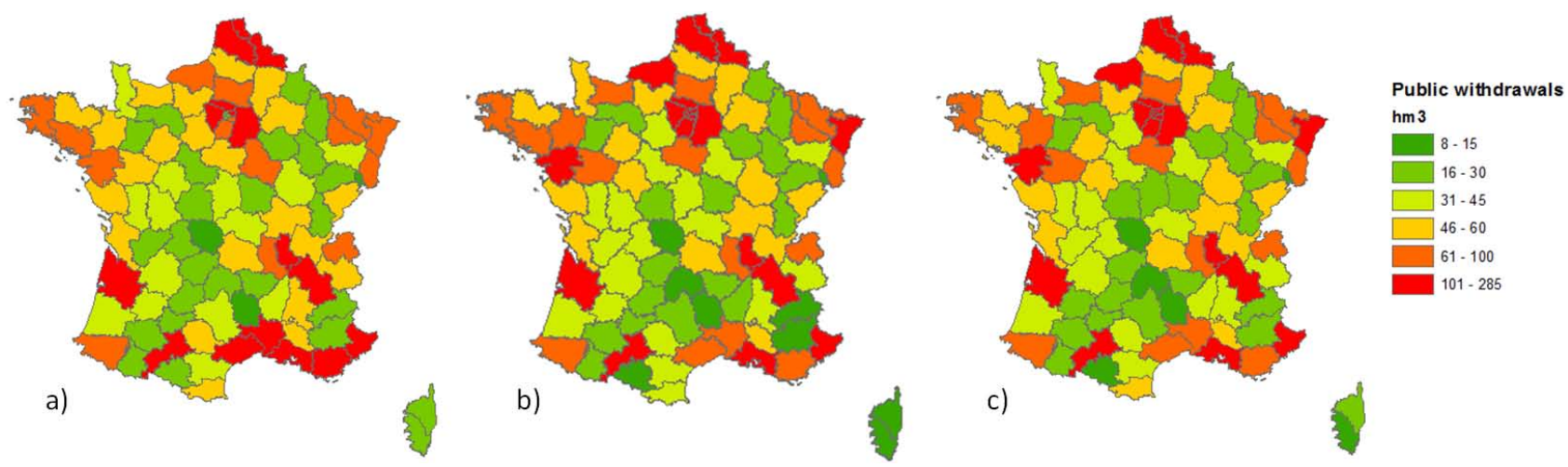

Fig. 6. Public water withdrawals given in hm3 for France at NUTS3 level for 2006. (a) NUTS3 totals derived from our model; (b) NUTS3 totals derived from disaggregation of water use directly to the population density; (c) actual statistical data available from the SOeS.

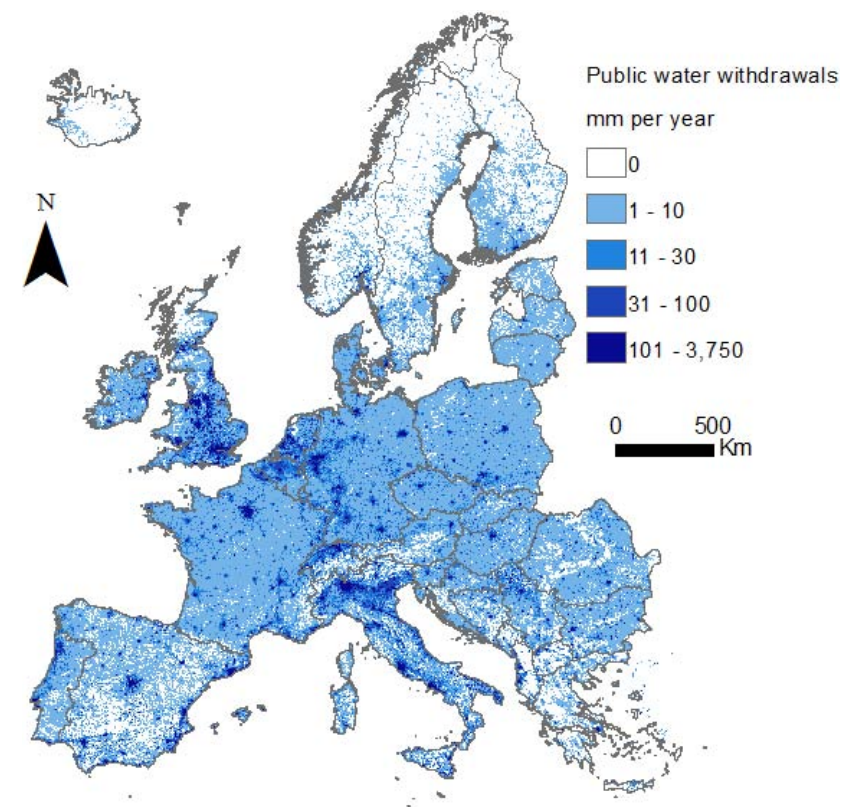

Fig. 7. Public water withdrawal at $5 \mathrm{~km}$ by $5 \mathrm{~km}$ resolution for 2006 in millimeters per year.

the highest water withdrawals, with the greatest withdrawals therefore being in major cities like London, Paris, Madrid, and Berlin. The Benelux area and northern Italy also stand out. The influence of tourism water withdrawals is seen especially in the high withdrawals along the coastal Mediterranean towns in Spain, Italy, and Croatia.

Tourism density can vary significantly depending on the region and the season. Figure 8 shows the tourism density maps for January and August of 2006 calculated for Italy. These months were selected to represent the peak winter and summer tourism. The Alps and the major towns retain high tourism densities for both seasons. In general, tourism is much greater in summer, with more tourists present in most regions, and an especially high concentration along the coastal towns. Summer tourism is especially high in the Veneto region of Italy and along the Croatian coast.

\subsection{Forecasted public water withdrawals for 2030}

The public water withdrawals were firstly forecasted and mapped keeping the country-level per capita water withdrawals constant, so that future total withdrawals were driven by the population and tourism trends. This represents a reference scenario, or a "worst-case scenario", where no improvement in water use efficiency with time is taken into account. Figure 9 shows the resulting evolution in public water withdrawals per NUTS2 region of the EU27 countries, calculated over the period from 2006 to 2030 . The difference in water withdrawals for 2030 to those made in 2006 varies from a decrease of up to $23 \%$ in central Germany and several regions in Poland, Hungary, Romania, Bulgaria, Latvia, Lithuania and Sweden, to an increase of up to $63 \%$ in southern Spain and France, northern and central Italy, the UK, and some regions of central and northern Europe.

Figure 10 compares the water withdrawal maps for 2006 and 2030 for Warsaw, Poland, at the original resolution of $100 \mathrm{~m}$ pixel size. Total public water withdrawals for the administrative region of Warsaw increase from $79.73 \mathrm{~h} \mathrm{~m}^{3}$ in 2006 to $81.65 \mathrm{~h} \mathrm{~m}^{3}$ in 2030 , an increase of about $2.4 \%$. This increase is directly related to the growth in population and tourism. The related, significant increase in urban areas is clearly visible when comparing the maps.

We additionally assessed two alternative scenarios that adjust the reference scenario to take future improvements in water use efficiency into account. Both scenarios look at the trend in per capita water withdrawals, which have been corrected by taking into account the actual total population that is connected to the public supply (EUROSTAT, 2013). The European average efficiency scenario assumes there will be a reduction in per capita water withdrawals over time, which is consistent with the average trend seen between 2000 and 2008 for 5 countries (France, Poland, Germany, UK, and Spain) that were assumed to be representative due to 


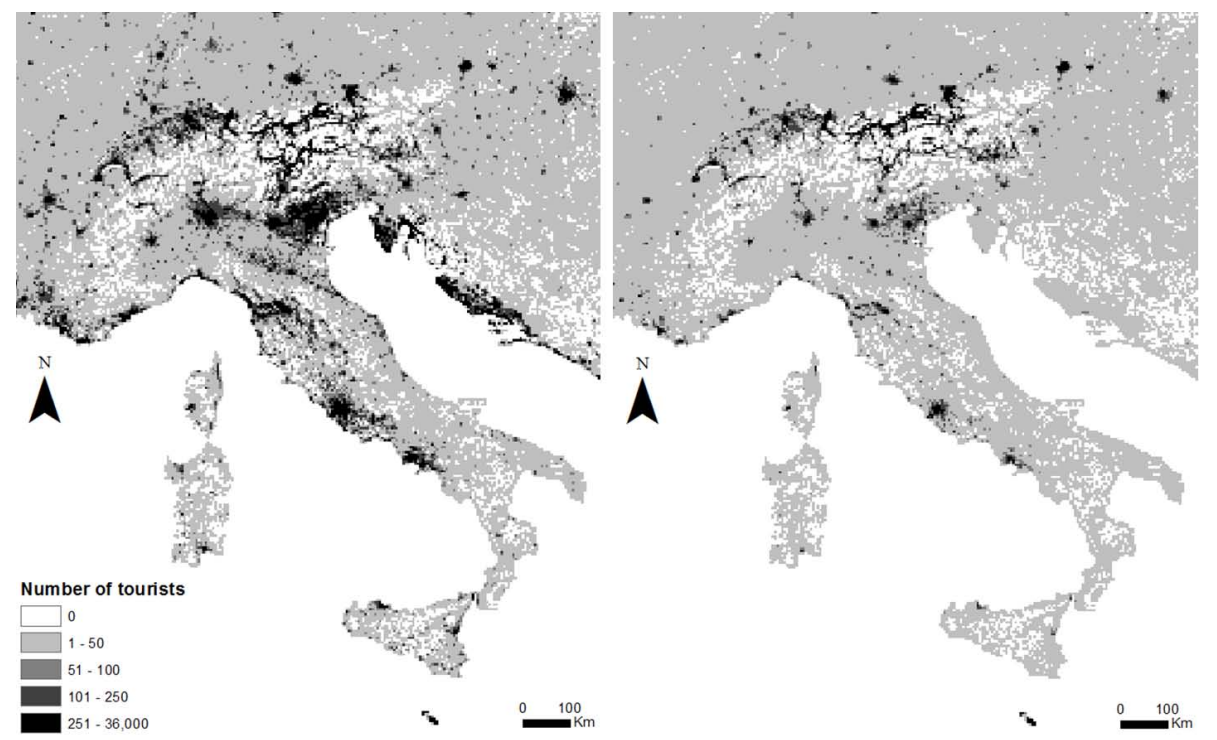

Fig. 8. Tourism density (number of tourists per $5 \mathrm{~km}$ pixel) for August 2006 (left panel), and January 2006 (right panel).

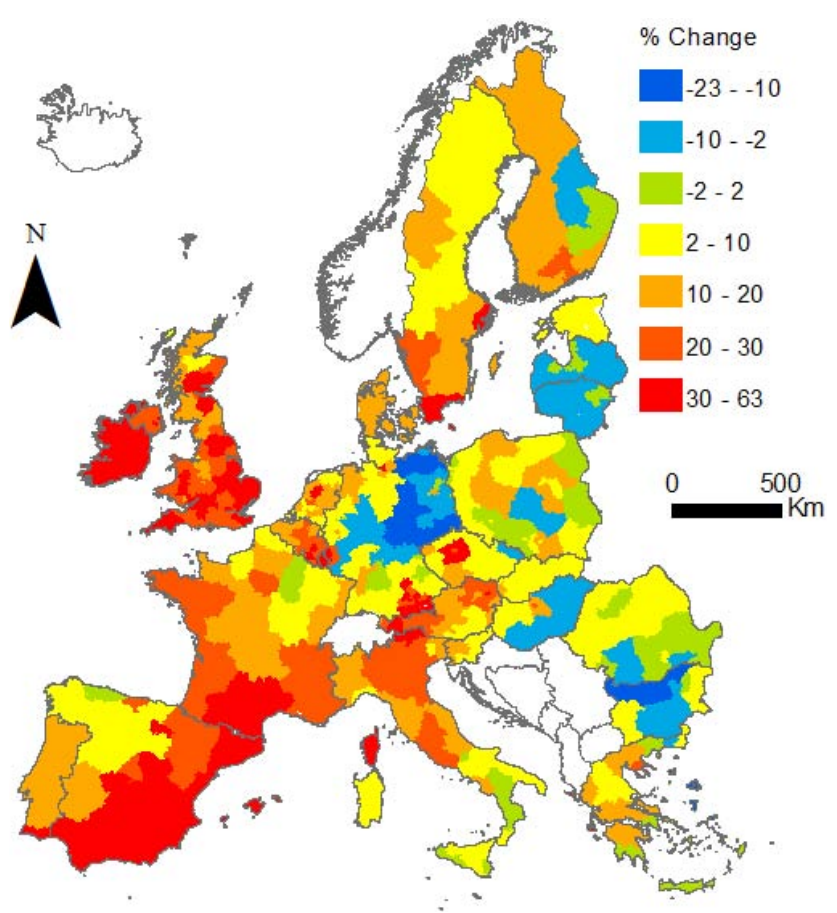

Fig. 9. The change in total public water withdrawals per NUTS2 region over the period from 2006 to 2030 (reference scenario) for the EU27 countries, given as a percentage increase or decrease.

their data consistency. We computed this average decreasing trend to be $0.86 \%$ annually, and corrected the resulting trend from the reference scenario accordingly. The convergence scenario assumes that per capita withdrawals will attain a minimal value or "optimal" efficiency by 2030 . We assumed the per capita withdrawal rate of Germany and Poland to be representativ in this case (both $64 \mathrm{~m}^{3} /$ person in 2006), since this is almost the lowest per capita withdrawal, and the data for both countries has been quite consistent over time. Countries already having lower per capita withdrawals than this (Estonia, Lithuania, Malta) were assumed to maintain their current water use efficiency. The additional impact that this convergence would have on the forecasted reference scenario was then computed per country. Figure 11 shows the resulting country-level change in total water withdrawals that is obtained in this way for each scenario for the period 2006-2030.

The scenarios show that there may in fact be a huge impact on future water withdrawals with increasing water use efficiency. If the current average European trend to reduce per capita withdrawals is taken into account (EU average efficiency scenario), the withdrawals forecasted are some $20 \%$ lower than those computed in the reference scenario for all countries. In fact, according to this scenario, only 5 countries (Sweden, UK, Spain, Luxemburg, and Ireland) would still have an increase in total public water withdrawals between 2006 and 2030. The convergence scenario results in the greatest forecasted reductions in total withdrawals, and highlights the countries that currently have relatively high per capita withdrawals, and thus where the most significant improvements could be made (e.g. in Romania, Bulgaria, and Italy).

\section{Discussion}

European public water withdrawals are mapped for the years 2006 (Fig. 7) and 2030 based on available land use, population and tourism data for 2006 and projections thereof to 2030. The monthly variation in public water withdrawals is 

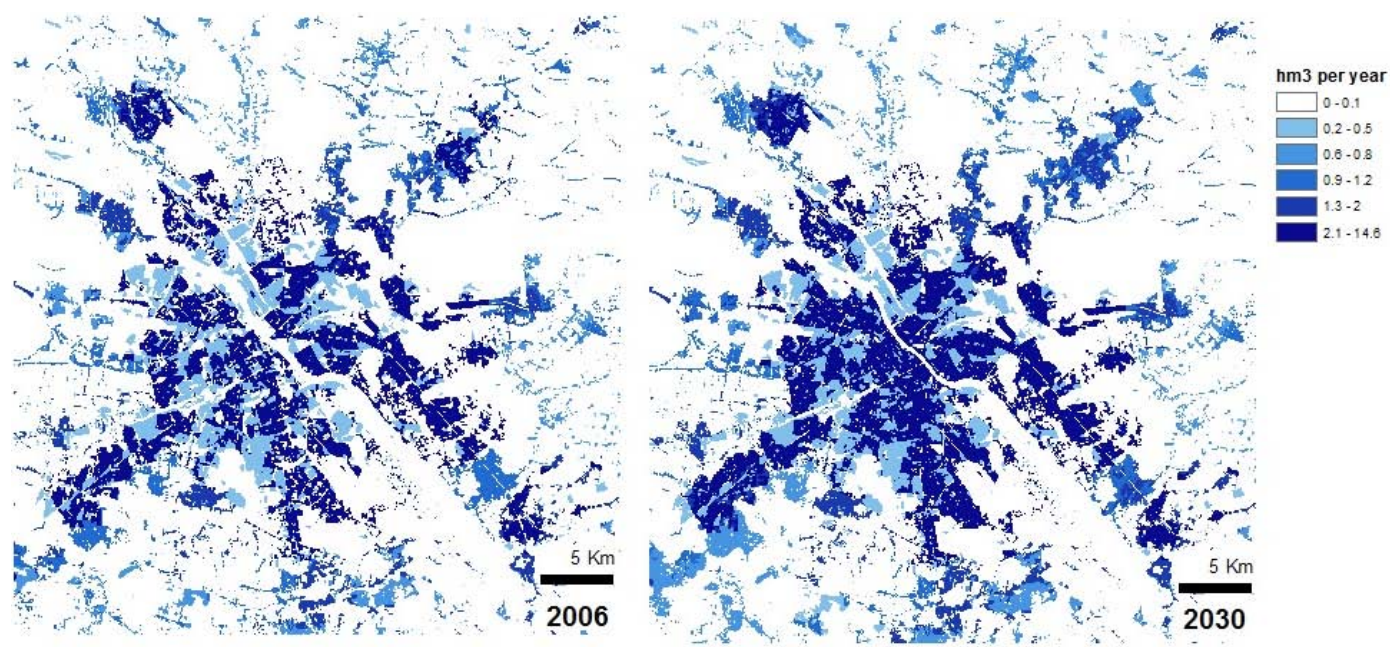

Fig. 10. Public water withdrawals modeled at $100 \mathrm{~m}$ resolution for Warsaw, Poland. The figure compares the withdrawals for 2006 (left panel) to those for the 2030 reference scenario (right panel).

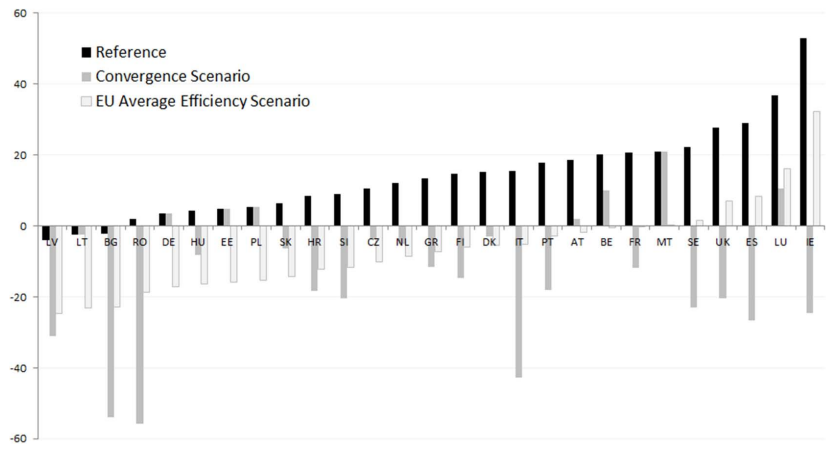

Fig. 11. The percentage change in annual public water withdrawals for 2030 as compared to 2006 for the reference computation and the two water use efficiency scenarios.

also taken into account - this variation is especially noticeable in terms of tourism densities, which are significantly higher in the summer, especially in coastal regions (Fig. 8). Our reference scenario forecasts considerable increases in public withdrawals in most countries, with central and Eastern Europe showing reasonably stable withdrawals, and overall decreasing trends predicted in Latvia, Lithuania and Bulgaria (Figs. 9, 11). These countries show relatively high tourism growth rates, but have strongly declining population trends resulting in overall decreasing water demand. Water withdrawals in southern Spain and France, northern Italy, and the UK are, however, predicted to increase considerably due to the combination of high population and tourism growth. In these regions increasing pressure is being put on the available resources and measures should be taken to reduce the impact of increasing water demand, especially considering the already limited supply of freshwater in the Mediterranean areas.
The European average trend in withdrawals for the period from 2006 to 2030 is an increase of $16 \%$ for our reference scenario. If we take into account an improvement in water use efficiency based on the average European trend between 2000 and 2008, we in fact see an average decrease in withdrawals of $4 \%$ over the same period. Furthermore, if we look at a scenario where the per capita water withdrawal per country would converge to an optimized rate by 2030 , the average change in total public water withdrawals would be further reduced to a decrease of $28 \%$. The actual total public water withdrawals to be recorded in 2030 will depend greatly on this varying water use efficiency.

The main limitation faced was the availability of detailed and up-to-date water withdrawal statistics. In the present study we used country-level data for public withdrawals as available regional data is limited in its consistency and comparability. We did, however, confirm the estimated withdrawals using actual regional statistics for France (Fig. 6). The total absolute error is 26.56 , or $13.3 \%$. Taking tourism into account reduces this error and improves the estimated withdrawals spatially. It also means that additional high water withdrawals are assigned to leisure facilities (which are often highly water intensive), which would otherwise not be included if disaggregation was only done based on the population density.

Future improvements to the methodology include looking further into the concept of water use efficiency and the factors that influence it. For example, investment in maintenance of distribution networks could greatly increase the efficiency of water use by reducing leakages. Total water losses during distribution vary greatly between countries, but, for example, Bulgaria, Greece, Malta, Ireland and the UK all show losses higher than the European average of $7.7 \%$ (EUROSTAT, 2013). Water pricing is increasingly being used to try to improve water use efficiency (Bithas, 2008), although the 
resulting impacts on the residential sector seem to be rather limited compared to those in the agricultural sector (Rinaudo et al., 2012; Höglund, 1999). In addition, we should see improvements in water use efficiency especially in regions currently experiencing water scarcity due to the greater necessity of limiting overall water use. The impact of changing regional water availability on future water demand is therefore an important additional aspect to be assessed (Rosegrant et al., 2002).

Although we present a robust methodology to forecast future public water withdrawals, we acknowledge that there are many uncertainties involved, especially considering that the methodology is dependent on land use, tourism, and population projections (Booth, 2006), which in turn have their own model uncertainties.

Edited by: M. Hipsey

\section{References}

Alcamo, J., Döll, P., Henrichs, T., Kaspar, F., Lehner, B., Rösch, T., and Siebert, S.: Development and Testing of the WaterGAP 2 Global Model of Water Use and Availability, Hydrolog. Sci., 48, 317-337, 2003.

Arbues, F., Garcia-Valinas, M. A., and Martinez-Espineira, R.: Estimation of residential water demand: a state-of-the-art review, J. Socio-Econ., 32, 81-102, 2003.

Batista e Silva, F., Lavalle, C., and Koomen, E.: A procedure to obtain a refined European land use/cover map, J. Land Use Sci., 8, 255-283, doi:10.1080/1747423X.2012.66745, 2012.

Batista e Silva, F., Gallego, J., and Lavalle, C.: A high resolution population grid map for Europe, J. Maps, 9, 16-28, doi:10.1080/17445647.2013.764830, 2013.

Bithas, K.: The sustainable residential water use: Sustainability, efficiency and social equity, the european experience, Ecol. Econ., 68, 221-229, 2008.

Booth, H.: Demographic forecasting: 1980 to 2005 in review, Int. J. Forecast., 22, 547-581, 2006.

EUROSTAT: http://epp.eurostat.ec.europa.eu/portal/page/portal/ statistics/, last access: 7 February 2013.

FAO AQUASTAT: The Food and Agriculture Organization of the United Nations' Information System on Water and Agriculture: http://www.fao.org/nr/water/aquastat/main/index.stm, Water withdrawal by sector; last access: 7 February 2013.

Flörke, M., and Alcamo, J.: European outlook on water use, Final Report, EEA/RNC/03/007, Center for Environmental Systems Research - University of Kassel, Kassel, Germany, 2004

Gleick, P. H.: Water Use, Annu. Rev. Environ. Resour., 28, 275314, doi:10.1146/annurev.energy.28.040202.122849, 2003.

GLOWASIS - The Global Water Scarcity Information Service FP 7 project co-ordinated by Deltares at Wageningen University, the Netherlands: www.glowasis.eu, last access: 15 January 2013.

Gössling, S., Peeters, P., Hall, C. M., Ceron, J. P., Dubois, G., Lehmann, L. V., and Scott, D.: Tourism and water use: supply, demand, and security, An international review, Tourism Manage., 33, 1-15, 2012.
Hoekstra, A. Y. and Mekonnen, M. M.: Global water scarcity: the monthly blue water footprint compared to blue water availability for the world's major river basinsm Value of Water Research Report Series No. 53, UNESCO-IHE, Delft, the Netherlands, 2011.

Höglund, L.: Household demand for water in sweden with implications of a potential tax on water use, Water Resour. Res., 35, 3853-3863, doi:10.1029/1999WR900219, 1999.

Kostas, B. and Chrysostomos, S.: Estimating urban residential water demand determinants and forecasting water demand for Athens metropolitan area, 2000-2010, S.-E. Eur. J. Econ., 1, 47-59, 2006.

Lavalle, C., Baranzelli, C., Batista e Silva, F. B., Mubareka, S., Gomes, C. R., Koomen, E., and Hilferink, M.: A High Resolution Land Use/Cover Modelling Framework for Europe: Introducing the EU-ClueScanner100 Model, in: Computational Science and Its Applications - ICCSA 2011, edited by: Murgante, B., Gervasi, O., Iglesias, A., Taniar, D., and Apduhan, B., Springer, Berlin, Heidelberg, 60-75, 2011.

Nagy, M., Lenz, K., Windhofer, G., Fürst, J., and Fribourg-Blanc, B.: Data Collection Manual for the OECD/Eurostat Joint Questionnaire on Inland Waters Tables 1-7, Concepts, definitions, current practices, evaluations and recommendations, Version 2.21, Publications Office of the European Union, Luxemburg, 2007.

Rinaudo, J., Neverre, N., and Montginoul, M.: Simulating the impact of pricing policies on residential water demand: A southern france case study, Water Resour. Manage., 26, 2057-2068, 2012.

Rosegrant, M. W., Cai, X., and Cline, S. A.: Global water outlook to 2025, International Food Policy Research Institute, Washington, D.C., USA, 2002.

Shiklomanov, I. A. (Ed.): Assessment of water resources and water availability in the world. Comprehensive assessment of the freshwater resources of the world, WMO and SEI, Stockholm, Sweden, 1997.

SOeS - Service de l'observation et des statistiques: statistique agricole annuelle pour la SAU, Ministere de L'ecologie, du developpement durable, des transports et du logement, available at: http://www.statistiques.developpement-durable.gouv.fr/ (last access: 5 December 2012), 2007.

UN WWDR - 3rd UN World Water Development Report: available at: http://unesdoc.unesco.org/images/0018/001819/181993e.pdf (last access: 20 November 2012), 2009.

Van Beek, L. P. H., Wada, Y., and Bierkens, M. F. P.: Global monthly water stress: 1 . Water balance and water availability, Water Resour. Res., 47, W07517, doi:10.1029/2010WR009791, 2009.

Wada, Y., van Beek, L. P. H., and Bierkens, M. F. P.: Modelling global water stress of the recent past: on the relative importance of trends in water demand and climate variability, Hydrol. Earth Syst. Sci., 15, 3785-3808, doi:10.5194/hess-15-37852011, 2011a.

Wada, Y., van Beek, L. P. H., Viviroli, D., Dürr, H. H., Weingartner, R., and Bierkens, M. F. P.: Global monthly water stress: II.Water demand and severity of water, Water Resour. Res., 47, W07518, doi:10.1029/2010WR009792, 2011b.

Wong, J. S., Zhang, Q., and Chen, Y. D.: Statistical modeling of daily urban water consumption in Hong Kong: Trend, changing patterns, and forecast, Water Resour. Res., 46, W03506, doi:10.1029/2009WR008147, 2010. 
WTO - World Tourism Organisation: Tourism Vision 2020 report Volume 4: Europe, WTO, Madrid, Spain, 2000.

Worthington, A. C., Higgs, H., and Hoffmann, M.: Modelling residential water demand in Queensland, Australia: A comparative analysis of pricing structures and estimation techniques, School of Accounting and Finance Working Paper Series No. 06/26, University of Wollongong, Wollongong, 2006.

Wriedt, G., Van Der Velde, M., Aloe, A., and Bouraoui, F.: Water Requirements for Irrigation in the European Union, EUR 23453 EN, OPOCE, Luxembourg, 2008. 